\title{
Study on cutting performance of SiCp/Al composite using textured YG8 carbide tool
}

\author{
Xu Wang ${ }^{1,2} \cdot$ Valentin L. Popov ${ }^{1,2} \cdot$ Zhanjiang $\mathrm{Yu}^{1} \cdot{\text { Yiquan } \mathrm{Li}^{1} \cdot \text { Jinkai Xu}}^{1} \cdot$ Huadong $\mathrm{Yu}^{1}$
}

Received: 17 June 2021 / Accepted: 5 November 2021 / Published online: 3 December 2021

(c) The Author(s) 2021

\begin{abstract}
Precision machining of $\mathrm{SiCp} / \mathrm{Al}$ composites is a challenge due to the existence of reinforcement phase in this material. This work focuses on the study of the textured tools' cutting performance on $\mathrm{SiCp} / \mathrm{Al}$ composite, as well as the comparison with non-textured tools. The results show that the micro-pit textured tool can reduce the cutting force by $5-13 \%$ and cutting length by $9-39 \%$. Compared with non-textured tools, the cutting stability of the micro-pit textured tools is better. It is found that the surface roughness is the smallest $(0.4 \mu \mathrm{m})$ when the texture spacing is $100 \mu \mathrm{m}$, and the residual stress can be minimized to around $15 \mathrm{MPa}$ in the case of texture spacing $80 \mu \mathrm{m}$. In addition, the $\mathrm{SiC}$ particles with size of around 2-12 $\mu \mathrm{m}$ in the $\mathrm{SiCp} /$ $\mathrm{Al}$ composite may play a supporting role between the texture and the chips, which results in three-body friction, thereby reducing tool wear, sticking, and secondary cutting phenomenon. At the same time, some SiC particles enter into the micropit texture, so that the number of residual particles on the surface is reduced and the friction between the tool and the surface then decreases, which improves the surface roughness, and reduces the surface residual stress.
\end{abstract}

Keywords $\mathrm{SiCp} / \mathrm{Al}$ composite $\cdot$ Micro-textured tool $\cdot$ Secondary cutting

\section{Introduction}

The $\mathrm{SiCp} / \mathrm{Al}$ composite material is mainly composed of aluminum alloy as the matrix and $\mathrm{SiC}$ particles as the reinforcing phase. Due to its special physical properties, including high hardness, low thermal expansion coefficient, high thermal conductivity, and high wear resistance, it has been widely used in aerospace, automotive, electronics, medical, optical instruments, and other fields [1-6]. The cutting process of $\mathrm{SiCp} / \mathrm{Al}$ composite is quite complicated. Due to the large elastoplasticity of the aluminum matrix and the high hardness of $\mathrm{SiC}$ particles, the tool is very quickly worn. Liu et al. [7] studied the influence of the position of the tool and the $\mathrm{SiC}$ particles on the cutting performance in the processing of $\mathrm{SiCp} / \mathrm{Al}$ composites, and found that when the tool was

Valentin L. Popov

v.popov@tu-berlin.de

$\triangle$ Zhanjiang Yu

13514310244@163.com

1 National and Local Joint Engineering Laboratory for Precision Manufacturing and Detection Technology, Changchun University of Science and Technology, Changchun 130012, Jilin, People's Republic of China

2 Technische Universität Berlin, 10623 Berlin, Germany located at a lower position in the middle of the $\mathrm{SiC}$ particles, the stress turned to greater, which can cause the entire $\mathrm{SiC}$ particles to break. Niu and Cheng [8] conducted milling experiments on $\mathrm{SiCp} / \mathrm{Al}$ composites. During the machining process, although the plastic deformation of the aluminum matrix can fill part of the pits caused by the $\mathrm{SiC}$ particles on the surface of the workpiece, there are still some defects on the surface. For a better application of the $\mathrm{SiCp} / \mathrm{Al}$ composite under a harsh working condition, it is important to study on its machining method [9].

A large number of experiments and theoretical explorations on the cutting performance of micro-textured tools and the lubrication performance of the surface have been conducted. Liu et al. [10] produced different textures on the flank face of cemented carbide tools, and further studied the wear resistance and machining surface quality of microtextured tools. They found that the flank face of the tool with textures is more excellent in terms of the wear resistance and surface machining quality. The parameters with good cutting performance are as follows: the groove width is $75 \mu \mathrm{m}$, the groove spacing is $100 \mu \mathrm{m}$, and the distance between the groove and the main cutting edge is $75 \mu \mathrm{m}$. Zhang et al. [11] prepared a sinusoidal groove micro-texture on the surface of cemented carbide using laser technology. 
They performed a linear reciprocating friction and wear test on the textured surface. The results showed that the surface of the sinusoidal micro-textured sample had the best wear resistance under the conditions of high load, high sliding speed under the condition of adding grease. Wu et al. [12] simulated the cutting process of micro-textured tool cutting Ti-6Al-4 V alloy using the finite element method, and carried out experimental verification. The results showed that micro-textured tools can reduce cutting temperature, cutting force, and tool-chip contact length. And it is easier to break the chips with the micro-textured tool. In addition, compared with the rectangular cross-section groove, the $\mathrm{V}$-shaped cross-section groove can reduce the severity of secondary cutting.

In addition, Zheng et al. studied the cutting performance of micro-textured tools for cutting Ti-6Al-4 V titanium alloy [13]. They selected YG8 tools and studied the cutting performance with four types of textured tools, namely, non-textured tools, line textured tools, sinusoidal textured tools, and rhombic textured tools. Among them, the groove width of the micro-textured tool is $159.599 \mu \mathrm{m}$ and the groove depth is $14.59 \mu \mathrm{m}$. It was found that the sinusoidal textured tool has the best cutting effect under different cutting parameters. It can reduce the cutting force and surface roughness, and extend the tool life. Feng et al. [14, 15] conducted cutting experiments on AISI 1045 steel based on micro-textured tools with transverse micro-texture morphology. The texture structure is as follows: $0.2 \mathrm{~mm}$ from the main cutting edge, $0.1 \mathrm{~mm}$ spacing, $0.1 \mathrm{~mm}$ width, and $0.1 \mathrm{~mm}$ depth. By designing positions, spacings, and widths of textures, the tool was finally obtained the best cutting performance. They found that the secondary cutting phenomenon is not obvious with the increasing groove width. The width of the groove and the cutting speed are the key factors that affect the secondary cutting during the machining. The measurement of cutting force, cutting temperature, workpiece surface roughness, and tool wear showed that compared with traditional tools, textured tools reduced cutting force, cutting temperature, tool wear significantly, and improved workpiece roughness. Vasumathy and Meena [16] studied the friction and adhesion of the tool-chip interface of AISI316 austenitic stainless steel during the machining. They found that the micro-textured tool can reduce the adhesion of the tool-chip, cutting force, and minimize the friction between the tool-chip interface. In order to study the effect of surface texture on Si3N4/TiC ceramics, Xing et al. $[17,18]$ prepared regularly arranged micro-grooves on the surface of Si3N4/TiC ceramics using a laser. It was showed that compared with the smooth surface, the textured surface can reduce the friction coefficient and improve the wear resistance of the material. And the tribological properties depend on the size and spacing of the micro grooves largely. To improve the friction and anti-adhesion of the tool rake face in the dry cutting of aluminum alloy, three textures on the cemented carbide rake face were created. It was found that the texture geometry has the greatest influence on the cutting force and friction coefficient in the cutting performance. Parida et al. [19] evaluated the cutting performance of Ti-6Al-4 V alloy micro-textured tools experimentally and numerically. The results showed that the contact length, friction coefficient, cutting force, and tool temperature distribution of the chip and the micro-textured tool were significantly reduced, compared with the flat tool. The cutting force, chip reduction coefficient, and chip morphology in the square result were consistented with the experimental results well. Sivaiah et al. [20] conducted a study on the cutting performance of the hybrid-textured tool and found that the friction between the textured tool and the chip was significantly reduced under wet cutting conditions, and the machined surface roughness was quite small. Elias et al. [21] proposed a new method to make texture on the cutting tools using vickers microhardness indenter.

Traditional cutting tools would produce large cutting forces and strong tool wear during machining [22, 23]. There are very few studies on the machining of $\mathrm{SiCp} / \mathrm{Al}$ composite using textured tools. In this work, the machining experiments of $\mathrm{SiCp} / \mathrm{Al}$ composite will be performed to investigate the cutting performance of $\mathrm{SiCp} / \mathrm{Al}$ composite with comparison to that of the non-textured tool. By preparing very small pits (about $5 \mu \mathrm{m}$ in diameter and $30 \mu \mathrm{m}$ in depth), the cutting performance of the tool and the surface quality of the workpiece will be studied. The influence of spacing on the cutting performance of micro-pit array textured tool will be investigated. The secondary cutting phenomenon will be observed, and the surface properties of the workpiece will be analyzed during the machining of SiCp/ Al composite to obtain the optimal texture parameters of the tool.

\section{Materials and methods}

The surface of the SiCp/Al composite after grinding and polishing is shown in Fig. 1. It can be seen that the $\mathrm{SiCp} / \mathrm{Al}$ composite is composed of an aluminum matrix and $\mathrm{SiC}$ particles. Due to the greater plasticity of the aluminum matrix and the high hardness of $\mathrm{SiC}$ particles, the aluminum matrix is removed during the polishing process, and the silicon carbide particles are exposed on the surface of the material. By measuring the SiC particles by the SEM, it is found that the size of the smallest $\mathrm{SiC}$ particles is about $2 \mu \mathrm{m}$, and the large $\mathrm{SiC}$ particles can reach about $12 \mu \mathrm{m}$. Moreover, some particles are pulled out and broken during the machining, which might interact with the textured tool and makes the micro-textured tool cutting process more complicated. This is completely different from the cutting of traditional metal 
Fig. 1 Image of $\mathrm{SiCp} / \mathrm{Al}$ composite structure after grinding and polishing under the SEM

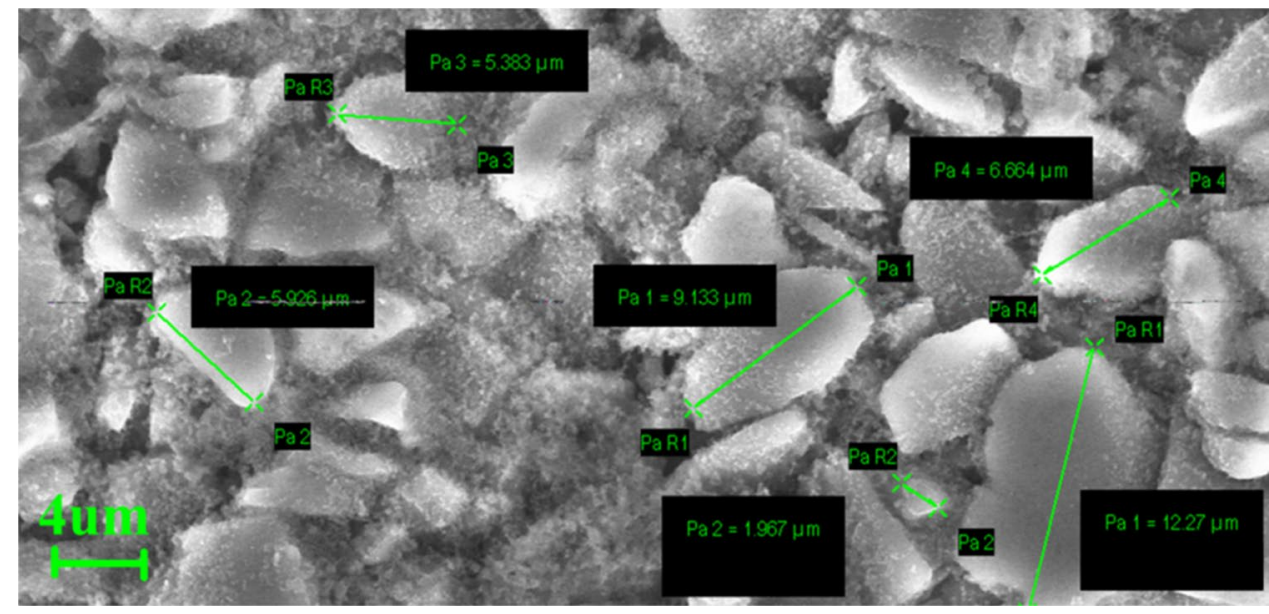

materials. The high hardness of $\mathrm{SiC}$ particles makes the tool wear very quickly and strong during the machining. The micro-textured tools cutting $\mathrm{SiCp} / \mathrm{Al}$ composite is studied in the following.

The micro-cutting experiment setup was developed which can be used to perform orthogonal cutting experiment, as shown in Fig. 2a. Figure 2 b gives a schematic diagram of the cutting process. The overall size of the orthogonal cutting table is $300 \times 400 \times 300 \mathrm{~mm}$, and size of the $X$ and $Y$ slide table is $70 \times 110 \mathrm{~mm}$. The stroke of slid table is $50 \mathrm{~mm}$, and its positioning accuracy is $2 \mu \mathrm{m}$, the repeated positioning accuracy is $0.5 \mu \mathrm{m}$, and the maximum feed speed is $400 \mathrm{~mm} / \mathrm{s}$. The size of the $Z$-direction lifting slide is $120 \times 120 \mathrm{~mm}$, the maximum ascent stroke is $12 \mathrm{~mm}$, the repeated positioning accuracy is $0.5 \mu \mathrm{m}$, and the bearing capacity is $20 \mathrm{~kg}$. The cutting force is measured by the Kistler cutting force measuring instrument.

In the experiment, the uncoated cemented carbide tool (NTK-KM1CCGW060202H) was used for machining. The rake angle is $7^{\circ}$, the flank angle is $3^{\circ}$, and a cutting-edge radius is $2 \mu \mathrm{m}$. Nanosecond pulsed fiber laser is used to manufacture the micro-pit texture on the rake face near the main cutting edge. The laser wavelength is $1.064 \mu \mathrm{m}$, the maximum output power is $20 \mathrm{~W}$, and the pulse frequency is $20-200 \mathrm{kHz}$.

The textured pits are as shown in Fig. 3. The pits are regularly distributed on the rake surface with different spacings. In this work, five values of pits spacing are investigated as follows: $100 \mu \mathrm{m}, 80 \mu \mathrm{m}, 60 \mu \mathrm{m}, 40 \mu \mathrm{m}$, and $20 \mu \mathrm{m}$. The other parameters are as follows. The diameter of the pit is around $5 \mu \mathrm{m}$ (green circle in Fig. 3a); the depth is around $30 \mu \mathrm{m}$ (Fig. 3b). The distance between the texture and the cutting edge is around $20 \mu \mathrm{m}$ (Fig. 3c). The workpiece size is $10 \times 10 \times 1 \mathrm{~mm}$ (cutting width $1 \mathrm{~mm}$ ), the cutting speed is set constant with $400 \mathrm{~mm} / \mathrm{s}$, the cutting depth is around $30 \mu \mathrm{m}$, and the cutting repeats 10 times. Table 1 numbers the textured tools with different pit spacing and the workpieces processed by different textured tools.

\section{Results and discussion}

Based on the experimental results, the wear of tool, contact length, secondary cutting, cutting force, and surface quality of workpieces were analyzed.

The surface of the tools was observed and inspected using a scanning electron microscope (SEM) after 10 cuttings. Figure $4 \mathrm{a}$ shows the surface of non-textured tool (T-1) after 10 cuttings, and Fig. 4b-f that of micro-textured tools with different spacing from 100 to $20 \mu \mathrm{m}$. It can be evaluated that the wear of tools and tool-chip adhesion are very serious during machining $\mathrm{SiCp} / \mathrm{Al}$ composite material. Among these six tools, the non-textured tool is worn most near the tool edge. Moreover, the amount of chip sticking on the surface of the non-textured tool is also the largest. It can be clearly seen from Fig. 4b-f that the micro-textured tool reduces not only tool wear during machining, but also the adhesion of tool surface effectively. The reduction of tool wear can be mainly attributed to the pit array which decreases the contact area and state between the tool and chip during the cutting process, thereby reduces the friction as well as the tool wear. The decrease in surface adhesion of the tool may be due to the effect of pits and $\mathrm{SiC}$ particles on chips during
Table 1 Numbers of tools and workpieces

\begin{tabular}{lllllll}
\hline Tool number & T-1 & T-2 & T-3 & T-4 & T-5 & T-6 \\
\hline Texture spacing & Non-textured & $100 \mu \mathrm{m}$ & $80 \mu \mathrm{m}$ & $60 \mu \mathrm{m}$ & $40 \mu \mathrm{m}$ & $20 \mu \mathrm{m}$ \\
Workpiece number & W-1 & W-2 & W-3 & W-4 & W-5 & W-6 \\
\hline
\end{tabular}


Fig. 2 (a) Orthogonal cutting experiment table. (b) Schematic diagram of machining

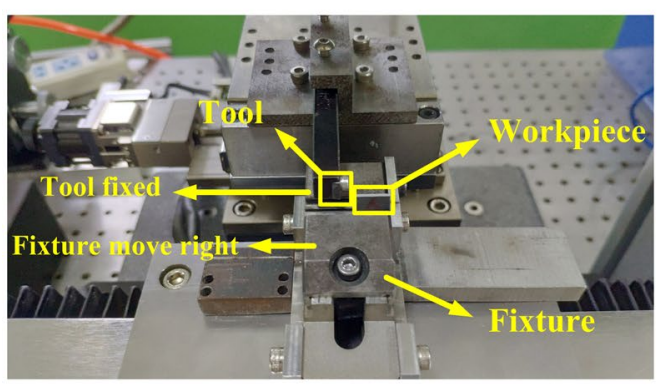

(a)

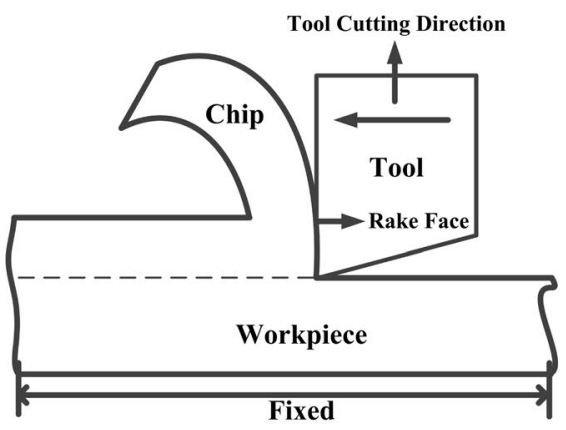

(b) the cutting process. Observing Fig. $4 \mathrm{e}$, it can be seen that the surface of the tool with a pit spacing of $40 \mu \mathrm{m}$ has very small amount of adhesion, and there is no adhesion around the micro-pit at the edge of the tool. Although some pits are blocked, the micro-pit array still plays an important role in reducing the adhesion condition of the cutting tool and chips.

Another reason for the reduction of tool surface adhesion may be due to the fact that some $\mathrm{SiC}$ particles play a supporting role between the tool and the chips, thereby reducing the direct contact between the tool and the chips. The adhesion phenomenon on the surface of the textured tool has been reduced in different ways, and the T- 5 tool is the most obvious. When the texture spacing increases from 40 to $100 \mu \mathrm{m}$, the anti-adhesion of the tool decreases. The main reason is that the texture area is reduced for large texture spacing; therefore, there is less texture interacting with chips. In the case of the texture spacing $20 \mu \mathrm{m}$, the texture is too dense, which leads to an increase in the concentrated stress on the surface of the chip, as well as an increase in the surface adhesion of the textured tool.

For that, the energy spectrum analysis of the sticking area on the surface of the micro-textured tool was carried out. As shown in Fig. 5, in addition to the elements of the tool material, the selected elements and the remaining elements are $\mathrm{Al}$ and $\mathrm{Si}$. From the distribution of $\mathrm{Si}$, it seems that some of the smaller $\mathrm{SiC}$ particles enter into the pit or attach on the surface of the micro-textured tool during the cutting process, then the SiC particles interact with the chip, which reduces the direct contact between the chip and the tool, resulting in a decrease in the adhesion on the surface of the microtextured tool.

\subsection{Contact length}

The tool-chip contact length of T-1 to T-6 tools during the cutting process is shown in Fig. 6. The distance between the position with the highest tool wear and the main cutting edge is selected as the tool-chip contact length. It can be seen that the micro-textured tool can reduce the toolchip contact length compared to the non-textured tool. The contact length is reduced by $39 \%, 22 \%, 30 \%, 32 \%$, and $9 \%$ for T-2 to T- 6 tools, respectively. The results show that the contact length for T-2 to T-5 tools is reduced significantly, and for T-2 tool, it is the smallest. During the machining of non-textured tools, the chips will break when they reach a wear state. However, the secondary cutting accelerates the chip's fracture. After the main cutting edge is machined, the micro-texture acts on the chip once again, which causes the breaking of chip before reaching the previous contact length. The texture changes the contact state of the bonding area. What actually changes is the curvature of the chips, which further affects the contact length between the chips. The main reason for the reduction in cutting length is that the texture will produce secondary cutting during the cutting process.

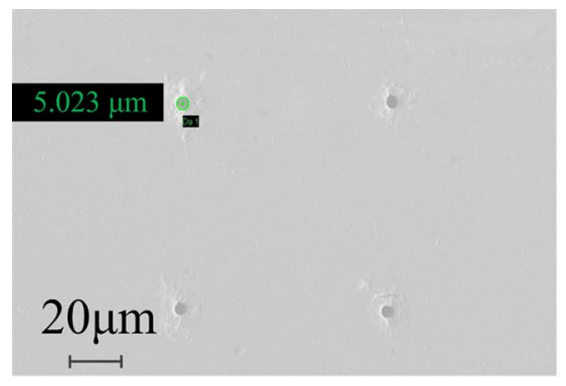

(a)

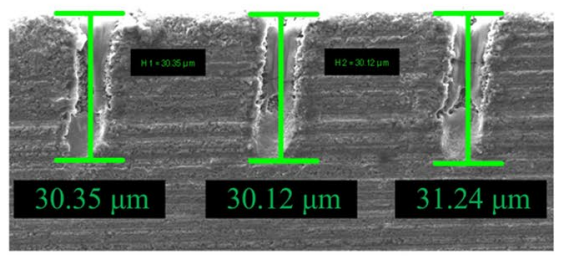

(b)

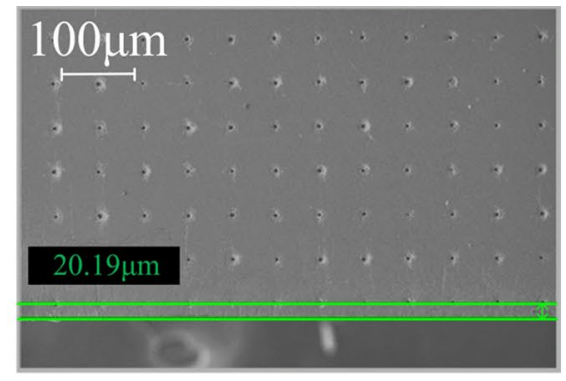

(c)

Fig. 3 (a) Top view of micro-textured pit diameter. (b) Profile of pit depth. (c) Distance between the micro texture and the main cutting edge 


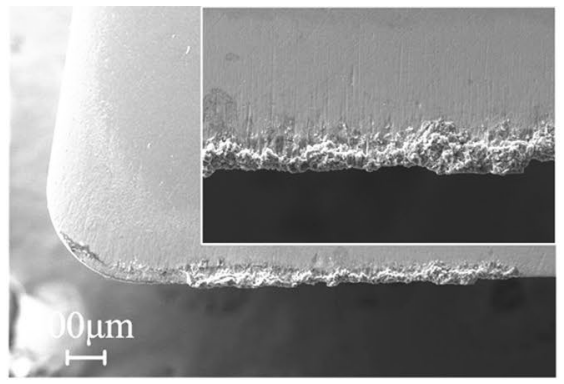

(a) $\mathrm{T}-1$

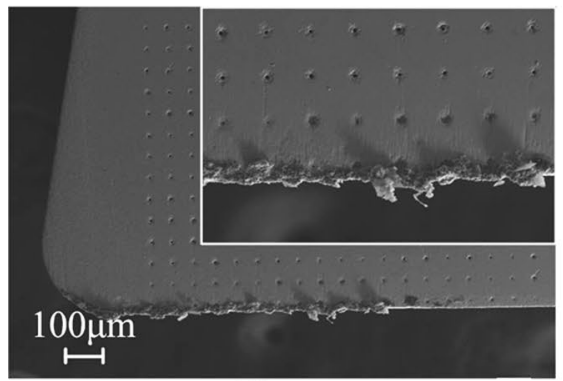

(d) $\mathrm{T}-4$

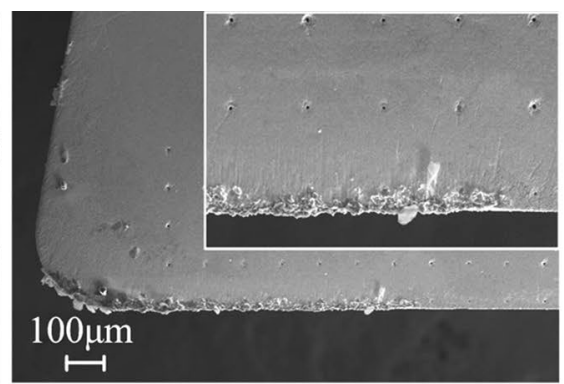

(b) $\mathrm{T}-2$

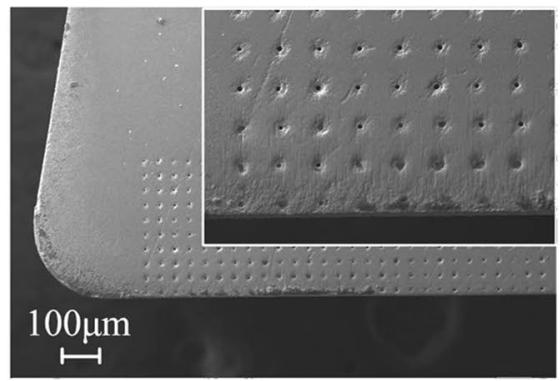

(e) T-5

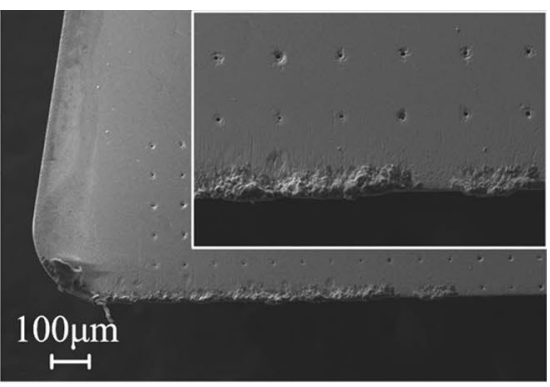

(c) $\mathrm{T}-3$

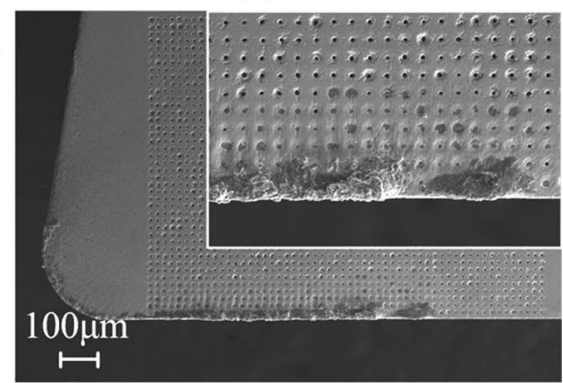

(f) $\mathrm{T}-6$

Fig. 4 SEM images of surfaces of non-textured and micro-textured tools after ten cuttings: (a) non-textured tools, (b) micro-textured tools with a pit spacing of $100 \mu \mathrm{m}$, (c) $80 \mu \mathrm{m}$, (d) $60 \mu \mathrm{m}$, (e) $40 \mu \mathrm{m}$, and (f) $20 \mu \mathrm{m}$

\subsection{Secondary cutting}

Secondary cutting is a common phenomenon in the cutting process of micro-textured tools. Comparing the chip surface micro morphology of Fig. 7a-f, it can be found that the chip surface machined by the textured tool will have textures with equal spacing. Therefore, it can be explained that the secondary cutting phenomenon will also occur in the process of machining $\mathrm{SiCp} / \mathrm{Al}$ composite. However, this phenomenon is not so obvious as for traditional metal. The main disadvantage of secondary cutting is that the chips will be cut again

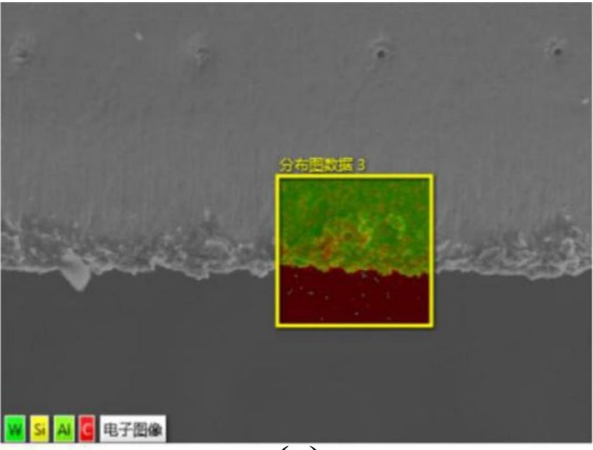

(a)

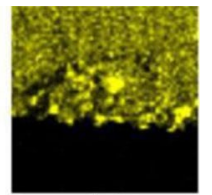

(b)

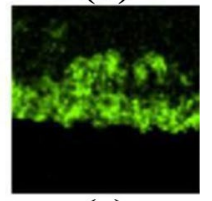

(c)
Fig. 5 (a) Energy spectrum analysis of micro-textured tool surface distribution of elements on the surface of micro-textured tools' edge. (b) Distribution of $\mathrm{Al}$ elements on the surface of micro-textured tools' edge. (c) Distribution of Si elements on the surface of microtextured tools' edge and new chips will be generated, leading to reducing the effectiveness of the micro-texture. From Fig. 7b-f, it can be seen that with the decrease of the micro-texture spacing, the phenomenon of secondary cutting becomes more obvious, which shows that too small texture spacing will increase the interaction between texture and chips. From Fig. 7c, e, T-3 and T-5 tools are more likely to break the chips during the cutting process, and then produce new chips. The secondary cutting phenomenon of T-2 and T-4 tools is not obvious

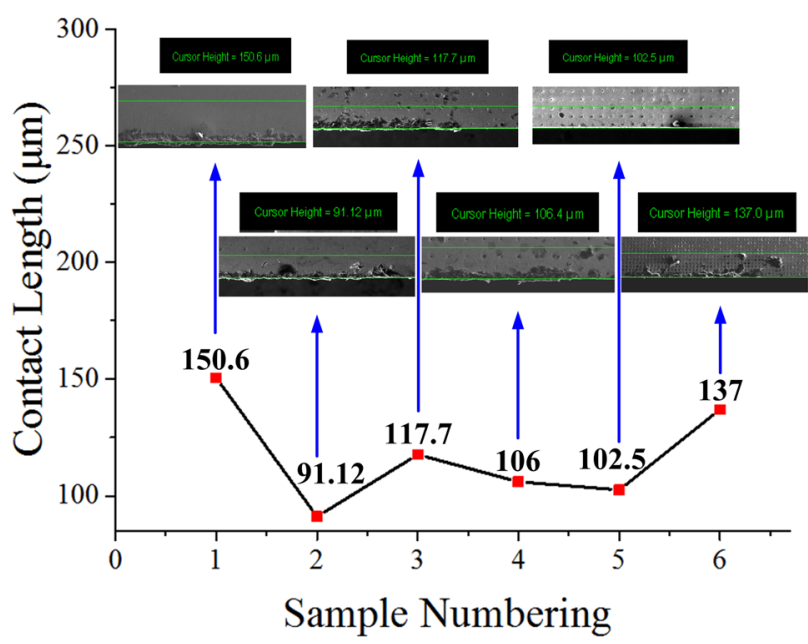

Fig. 6 Tool-chip contact length during the cutting process of nontextured tool and micro-textured tool. Numbering 1-6 corresponds to Tool T-1 to T-6, respectively 


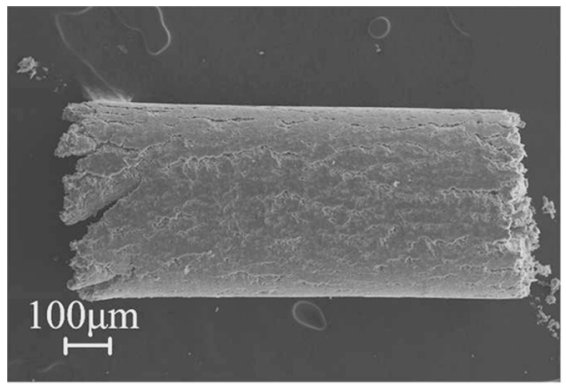

(a)

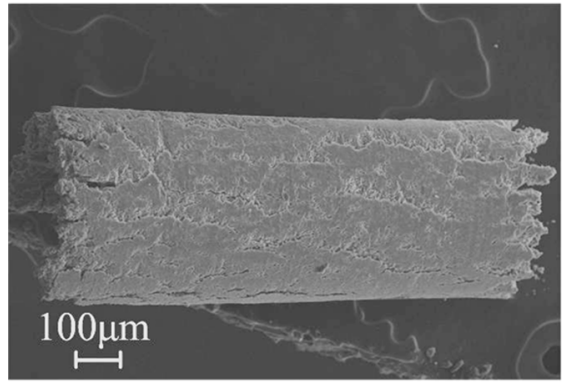

(d)

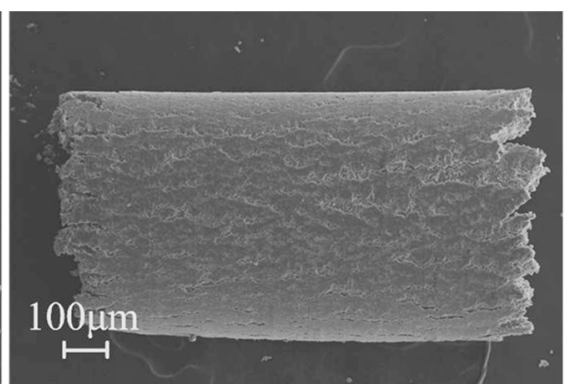

(b)

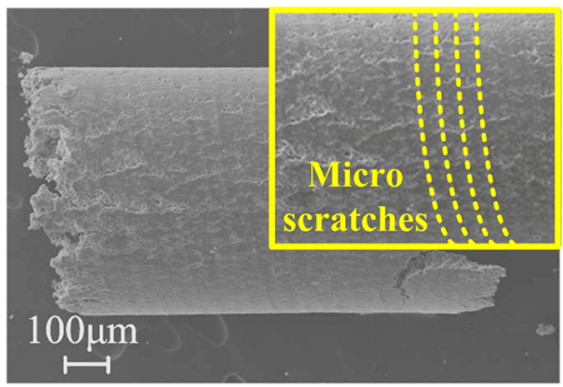

(e)

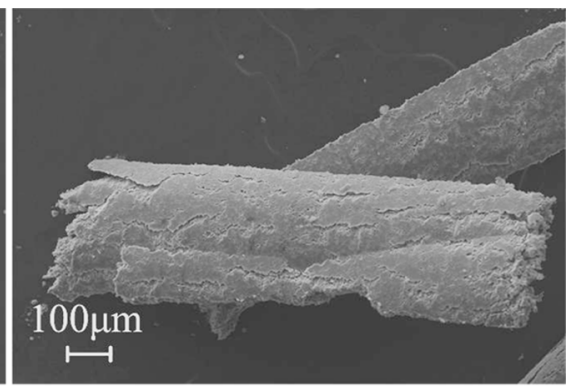

(c)

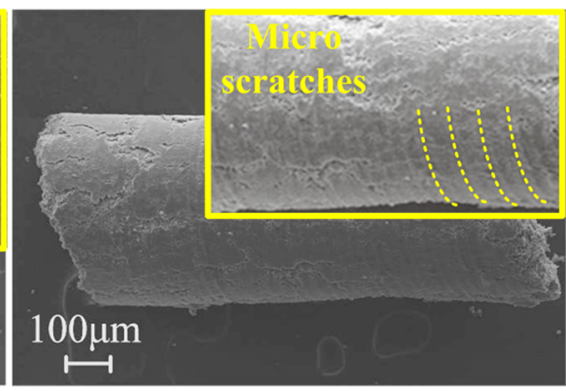

(f)

Fig. 7 SEM images of chips generated during the cutting process of non-textured tools and micro-textured tools. Chips produced by (a) T-1 tool, (b) T-2 tool, (c) T-3 tool, (d) T-4 tool, (e) T-5 tool, and (f) T-6 tool

during the cutting process, and the chips are not easily broken. The most obvious secondary cutting phenomenon is in Fig. 7e, f. It is further explained that adjusting the texture spacing can achieve the required cutting effect.

Due to the particularity of the $\mathrm{SiCp} / \mathrm{Al}$ composite, the secondary cutting process could be divided into two cases, as showed in Fig. 8. In the first case, the micro-texture pits are not blocked, so the micro-texture will directly interact with the chips during the cutting process. Then some of the pits will be blocked, which greatly reduces the effect of the pits. In the second case, some broken particles and particles remaining on the chip surface may interact with the tool surface or the pit texture. This reduces the tool surface adhesion and tool-chip contact length. Since the second case works differently from the first case, the reduction in contact length should be due to the simultaneous action of these two stages. However, due to the property of the material, the second stage could play a major role.

\subsection{Cutting force}

Cutting force is the main factor affecting tool wear. In the experiment, the machining direction is set as the direction of main cutting force, and its values are averaged after
Fig. 8 Schematic diagram of secondary cutting of SiCp/Al composite with micro-textured tool. (a) Initial stage of secondary cutting. (b) Stable stage of secondary cutting

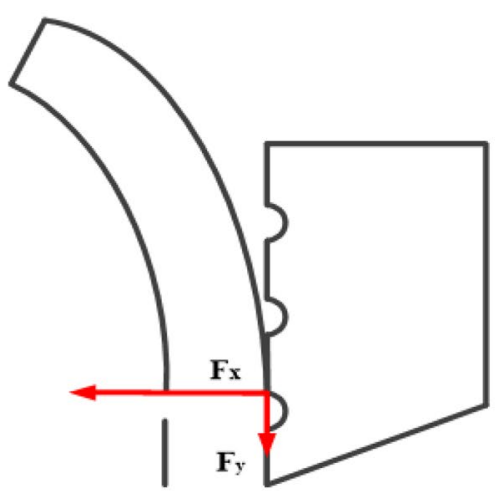

(a)

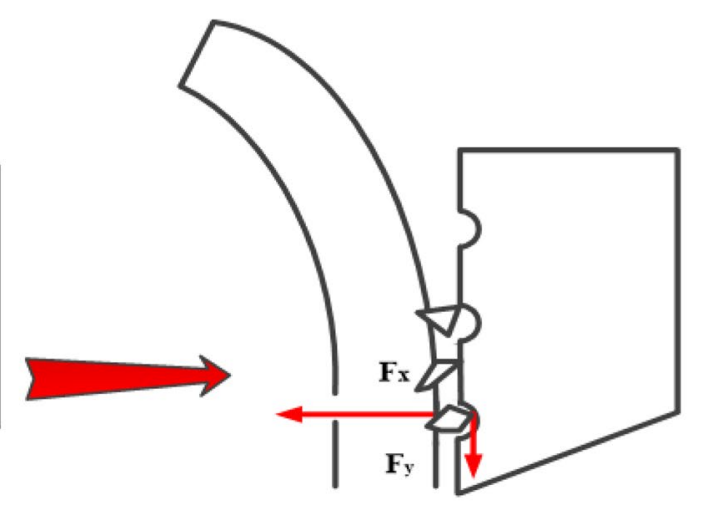

(b)

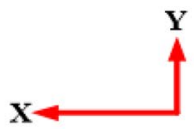




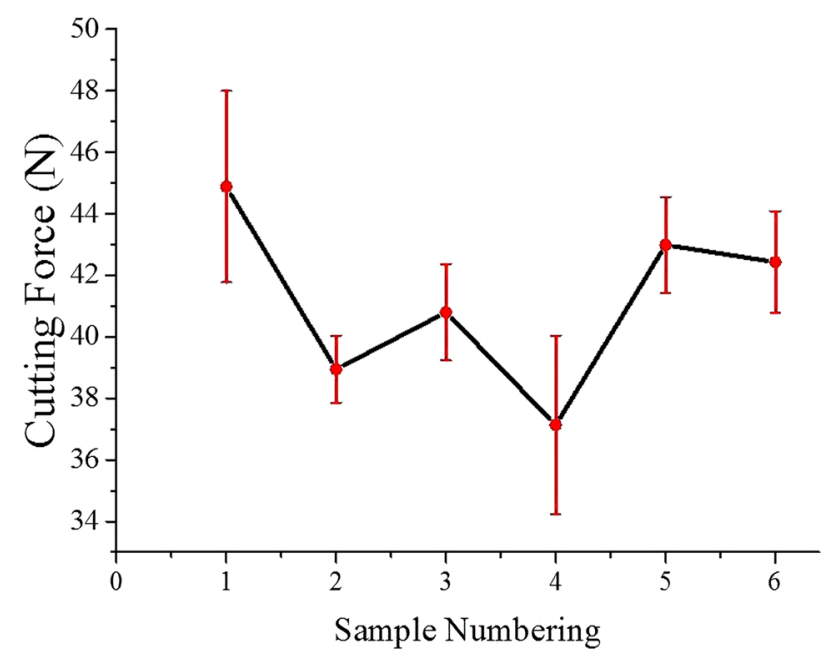

Fig. 9 The average value of the main cutting force during the cutting process of the non-textured tool and the micro-textured tool. Numbering 1-6 represents the cutting force generated by the T-1 to T-6 tools

ten times cuttings. The results are shown in Fig. 9. It is seen that T-2 to T- 6 tools produce smaller cutting forces than T-1 tool. The micro-textured tool reduces the friction between the tool and the chip during the machining, thereby reducing the cutting force. With the decrease in the micro-texture spacing, the cutting force of the microtextured tool is reduced by $13 \%, 9 \%, 17 \%, 4 \%$, and $5 \%$, respectively. The cutting forces of T-5 and T- 6 tools are not reduced significantly due to the secondary cutting during the cutting process. In the cutting process, for the T-3 tool, it is easy to break chips. Observing the chip morphology produced by T-2 and T-4 tools, one can evaluate that these two micro-textured tools are more stable during the cutting process, which will result in a significant reduction in cutting force. From the results of chip shape and cutting force, the texture spacing will influence the contact state of the sticking area, further reduce the cutting force. The SiC particle, pit, and chip may form a threebody friction for the reducing cutting force.

\subsection{Workpiece surface test}

Figure 10 presents the SEM images of the surface of the workpiece after cutting. It can be seen that the surfaces machined by the micro-textured tools are generally smooth and have a few cracks relatively (Fig. 10b, c, e, f). In the following, it will be shown that the residual $\mathrm{SiC}$ particles on the machining surface of micro-textured tools are much less than non-textured tool, and part of the $\mathrm{SiC}$ particles remain in the pit and interact with the chips during the cutting process.

\subsection{Surface roughness}

Surface roughness is an important criterion for measuring the quality of workpiece machining. The measurement method is contact measurement. Five different positions are

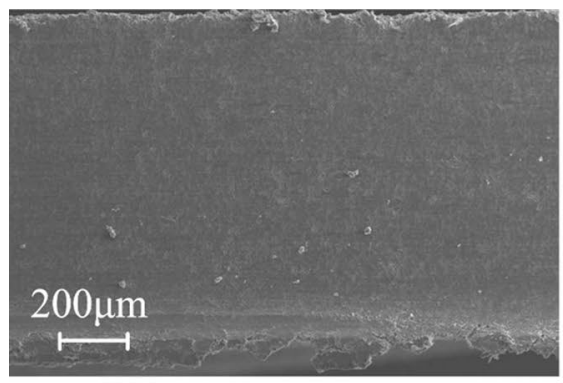

(a)

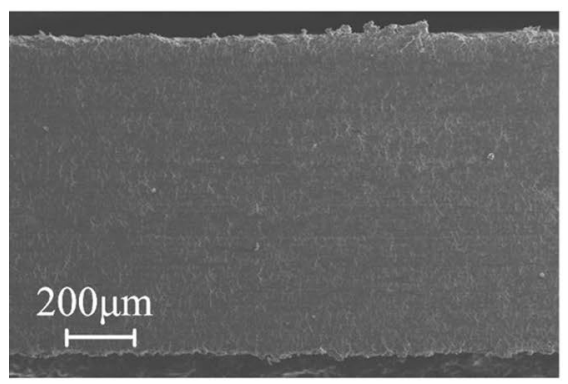

(d)

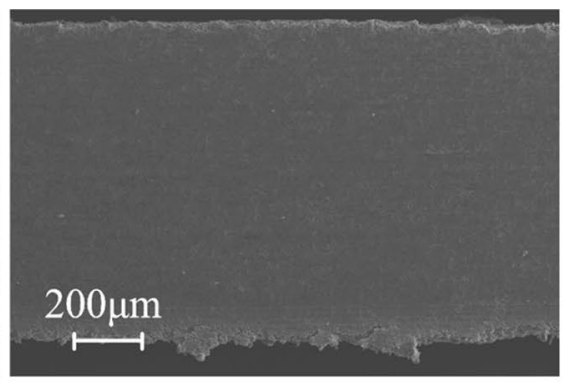

(b)

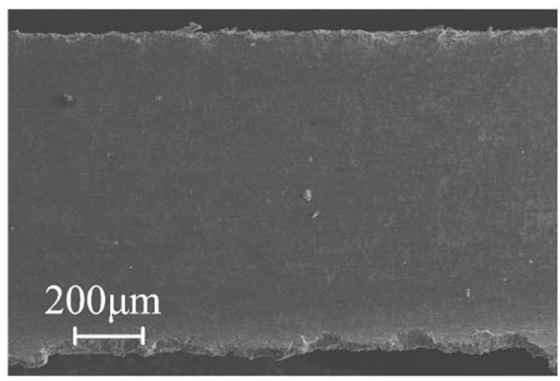

(e)

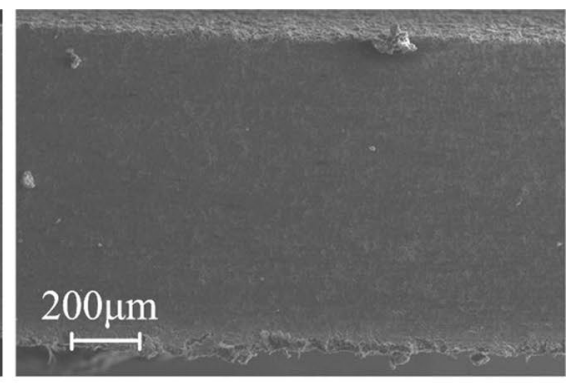

(c)

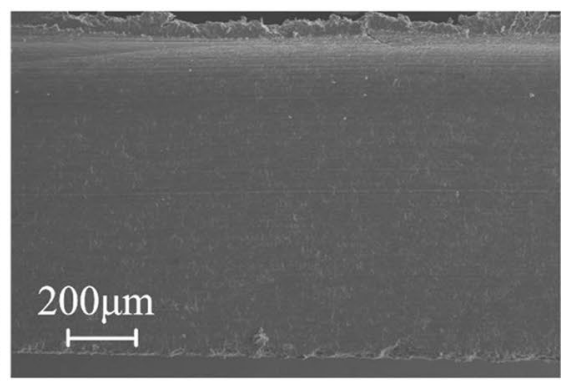

(f)

Fig. 10 SEM images of non-textured tool and micro-textured tool surface: (a) W-1, (b) W-2, (c) W-3, (d) W-4, (e) W-5, and (f) W-6 


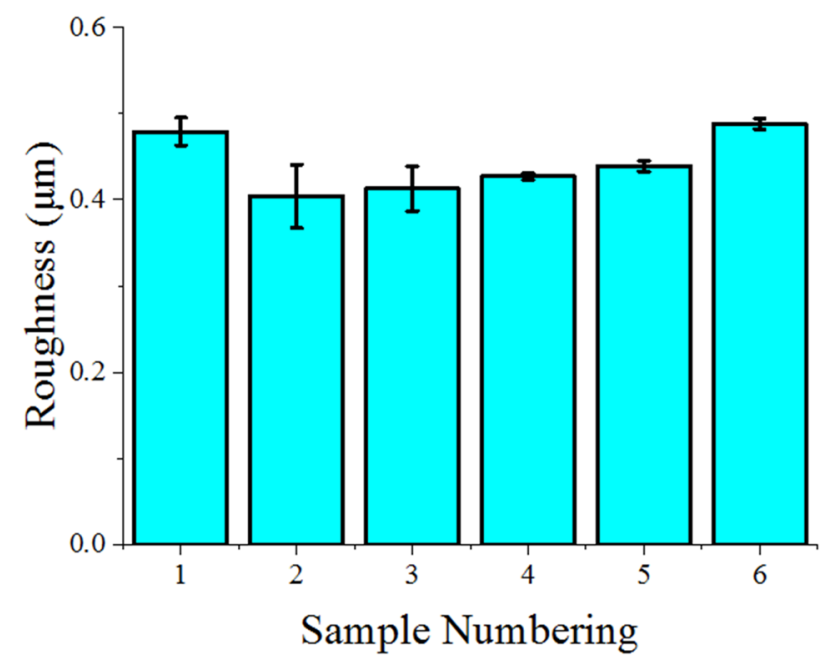

Fig. 11 Surface roughness of workpieces machined by non-textured tool and micro-textured tools. (a) W-1, (b) W-2, (c) W-3, (d) W-4, (e) W-5, and (f) W-6

selected on the surface of the workpiece for measurement, and the results are averaged. Figure 11 shows the Ra values of surface roughness workpieces W-1 to W-6. Ra is the arithmetic average of the absolute value of the contour deviation along the measurement direction and the distance from the center line, and can be used to evaluate the smoothness of machined parts. It can be seen that the surface roughness of $\mathrm{W}-1$ workpieces is relatively large, and smaller for W-2 to $\mathrm{W}-6$, which is consistent with the observation of the surface micro-topography (Fig. 10). Because the micro-pit texture of the tool can collect some $\mathrm{SiC}$ particles, the interaction between the tool, $\mathrm{SiC}$ particles, and the surface of the workpiece is reduced. The surface roughness is reduced. With the decrease of the texture spacing, the secondary cutting effect produced by the texture and chip surface is more obvious. The surface will produce greater concentrated stress, and the surface roughness will become worse.

\subsection{Residual stress}

The residual stress of the machined workpiece is measured by a residual stress measuring instrument, which receives the signal of the machined metal surface and calculates the surface stress through the Bragg's law. Since the stress of the $\mathrm{SiC}$ particles in the $\mathrm{SiCp} / \mathrm{Al}$ composite material cannot be measured, so the stress distribution of the aluminum matrix in the $\mathrm{SiCp} / \mathrm{Al}$ composite material is measured instead. It can be seen from the results that the textured tool has a certain influence on the residual stress of the machined surface. It can be seen from Fig. 12 that this detection plan is to select 5 points on the surface of the workpiece with an interval of $0.25 \mathrm{~cm}$, the position of the leftmost point is $0 \mathrm{~cm}$, and the position of the rightmost point is $1 \mathrm{~cm}$. It can be seen that when the texture spacing is $60-100 \mu \mathrm{m}$, the residual stress on the machined surface of the workpiece is smaller than that of a non-textured tool but when the spacing is $20-40 \mu \mathrm{m}$, the residual stress on the machined surface of the workpiece tends to increase. It can be observed from the surface of the chip that the secondary cutting phenomenon is the most serious when the texture spacing is $20-40 \mu \mathrm{m}$.

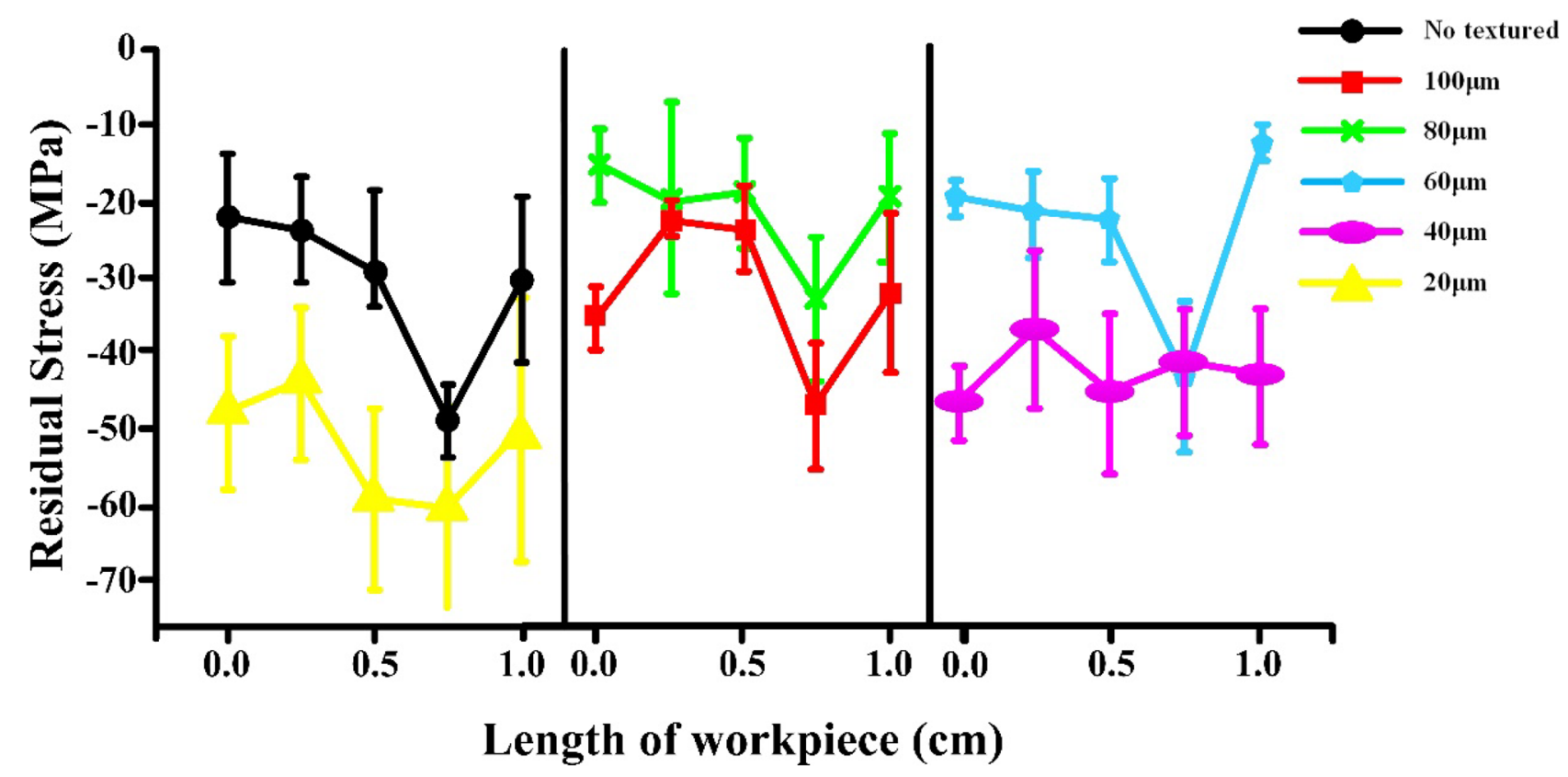

Fig. 12 Surface residual stress of workpieces machined by non-textured tools and micro-textured tools 
With the spacing decrease, the contact state of the sticking area will change; the stress between the tool and the chip becomes larger, which increases the machined surface residual stress of the workpiece.

\section{Conclusion}

In this paper, a micro-pit array textured tool with a diameter of $5 \mu \mathrm{m}$ is applied to the machining of $\mathrm{SiCp} / \mathrm{Al}$ composite. Micro-textured tools can not only improve the cutting performance of the tool, but also improve the surface quality of the workpiece. Considering the cutting performance and surface quality, the T-5 tool shows better tool properties. The conclusions are the following:

1. Serious tool wear and adhesion occurred during dry cutting $\mathrm{SiCp} / \mathrm{Al}$ composite; however, by using microtextured tools, they can be reduced significantly. It is attributed to the interaction between the micro-pit, $\mathrm{SiC}$ particles, and the chips.

2. The contact length between the tool and the chip in the non-texture case is the largest during the cutting process. The micro-textured tools can reduce the contact length through the micro pits.

3. Micro-textured tools produce secondary cutting during cutting process. Increasing the pit spacing of microtextured tool can reduce the impact of secondary cutting. Main cutting force is reduced by use of microtexture. The cutting force is reduced largest by $17 \%$ in the case of the tool with spacing $60 \mu \mathrm{m}$ (T-4). Spacing $40 \mu \mathrm{m}$ is a turning point for anti-adhesion. The texture anti-adhesion becomes worse when the spacing exceeds or is less than $40 \mu \mathrm{m}$.

4. The micro-pits texture can collect $\mathrm{SiC}$ particles, which reduces the number of residual particles on the surface of the workpiece, as well as the interaction between $\mathrm{SiC}$ particles, tool, and workpiece for improving the surface quality. This interaction is enhanced with the decreasing texture spacing, which causes greater concentrated stress on the chip surface, further aggravates the secondary cutting phenomenon. However, too small texture spacing could change the contact state of the sticking area, causing greater residual stress on the workpiece's surface. Focusing on the tool life, T-5 shows the best cutting performance.

Author contribution V.L. Popov and Xu Wang designed the experimental plan, and Zhanjiang Yu and Jinkai Xu designed and adjusted the experiment set-up. The measurement was performed by Jinkai Xu, Yiquan $\mathrm{Li}$, and $\mathrm{Xu}$ Wang. V.L. Popov and Zhanjiang Yu processed and analyzed the experimental data. Huadong Yu supervised the project and the collaboration.
Funding Open Access funding enabled and organized by Projekt DEAL. This work was supported by the National Key Research and Development Plan Project (No. 2018YFB1107403), the "111" Project of China (No. D17017), Jilin Province Scientific and Technological Development Program (No. 20190101005JH, No. 20180201057GX, No. 20190302076GX), and Science Fund for Youth Scholar of Changchun University of Science Technology (No. XQNJJ-2018-09).

Availability of data and materials The data that support the findings of this study are available from the corresponding author upon reasonable request.

\section{Declarations}

Ethical approval Not applicable.

Consent to participate Not applicable.

Consent to publish Not applicable.

Competing interests The authors declare no competing interests.

Open Access This article is licensed under a Creative Commons Attribution 4.0 International License, which permits use, sharing, adaptation, distribution and reproduction in any medium or format, as long as you give appropriate credit to the original author(s) and the source, provide a link to the Creative Commons licence, and indicate if changes were made. The images or other third party material in this article are included in the article's Creative Commons licence, unless indicated otherwise in a credit line to the material. If material is not included in the article's Creative Commons licence and your intended use is not permitted by statutory regulation or exceeds the permitted use, you will need to obtain permission directly from the copyright holder. To view a copy of this licence, visit http://creativecommons.org/licenses/by/4.0/.

\section{References}

1. Muthukrishnan N, Murugan M, Rao KP (2008) Machinability issues in turning of Al-SiC (10p) metal matrix composites. Int J Adv Manuf Syst 39(3-4):211-218

2. Goo BC (2016) Al/SiCp brake discs produced by dissimilar castbonding. Mater Manuf Process 31(10):1318-1323

3. Hong SJ, Kim HM, Huh D, Suryanarayana C, Chun BS (2003) Effect of clustering on the mechanical properties of $\mathrm{SiC}$ particulatereinforced aluminum alloy 2024 metal matrix composites. Mater Sci Eng A 347(1-2):198-204

4. Tosun G (2011) Statistical analysis of process parameters in drilling of $\mathrm{Al} / \mathrm{SiCp}$ metal matrix composite[J]. Int J Adv Manuf Technol 55(5-8):477-485

5. Zhou M, Wang M, Dong GJ (2015) Experimental investigation on rotary ultrasonic face grinding of $\mathrm{SiCp} / \mathrm{Al}$ composites. Mater Manuf Process 31(5):673-678

6. John R, Lin R, Jayaraman K, Bhattacharyya D (2020) Effects of machining parameters on surface quality of composites reinforced with natural fibers. Mater Manuf Process 36(2):73-78

7. Liu JW, Cheng K, Ding H, Chen SJ, Zhao L (2018) Simulation study of the influence of cutting speed and tool-particle interaction location on surface formation mechanism in micromachining SiCp/Al composites. Proc IMechE Part C: J Mech Eng Sci 232(11):2044-2056 
8. Niu ZC, Cheng K (2019) An experimental investigation on surface generation in ultraprecision machining of particle reinforced metal matrix composites. Int J Adv Manuf Technol 105:4499-4507

9. Seeman M, Ganesan G, Karthikeyan R, Vealyudham A (2010) Study on tool wear and surface roughness in machining of particulate aluminum metal matrix composite-response surface methodology approach. Int J Adv Manuf Technol 48(5-8):613-624

10. Liu Y, Deng J, Wang W, Duan R, Meng R, Ge D, Li X (2018) Effect of texture parameters on cutting performance of flank-faced textured carbide tools in dry cutting of green $\mathrm{Al} 2 \mathrm{O} 3$ ceramics. Ceram Int 44(11):13205-13217

11. Zhang GL, Deng JX, Ge DL, Wang W, Zhang X, Liu YY (2018) Effect of sine-type surface macrotexture on tribological property of carbide. Tool Eng 52(2):12-17

12. Wu Z, Bao H, Liu L, Xing YQ, Huang P, Zhao GL (2020) Numerical investigation of the performance of micro-textured cutting tools in cutting of Ti-6Al-4V alloys. Int J Adv Manuf Technol 108(10):463-474

13. Zheng KR, Yang FZ, Zhang N, Liu QY, Jiang FL (2020) Study on the cutting performance of micro textured tools on cutting Ti-6Al-4V Titanium Alloy. Micromachines 11:137

14. Feng YH, Zhang JY, Wang L, Zhang WQ, Dong YP (2019) Study on secondary cutting phenomenon of micro-textured self-lubricating ceramic cutting tools with different morphology parameters formed via in situ forming of Al2O3-TiC. Int J Adv Manuf Technol 104:3821-3833

15. Feng YH, Yuan PD, Wang L, Zhang JY, Zhang JH, Zhou X (2020) Experimental investigation of different morphology textured ceramic tools by in-situ formed for the dry cutting. Int $\mathbf{J}$ Appl Ceram Technol 17:1108-1118
16. Vasumathy D, Meena A (2017) Influence of micro scale textured tools on tribological properties at tool-chip interface in turning AISI 316 austenitic stainless steel. Wear 376-377:1747-1758

17. Xing YQ, Deng JX, Feng XT, Yu S (2013) Effect of laser surface texturing on $\mathrm{Si} 3 \mathrm{~N} 4 / \mathrm{TiC}$ ceramic sliding against steel under dry friction. Mater Des 52:234-245

18. Xing YQ, Deng JX, Wang XS, Ehmann K, Cao J (2016) Experimental assessment of laser textured cutting tools in dry cutting of aluminum alloys. J Manuf Sci Eng 138(7):071006

19. Parida AK, Rao PV, Ghosh S (2020) Performance of textured tool in turning of Ti-6Al-4V alloy: numerical analysis and experimental validation. J Braz Soc Mech Sci Eng 42(5):715-725

20. Sivaiah P, Muralidhar SM, Venkatesu S, Yoganjaneyulu G (2020) Investigation on turning process performance using hybrid-textured tools under dry and conventional cooling environment. Mater Manuf Process 35(16):1852-1859

21. Elias JV, Prasanna VN, Deepak LK, Jose M (2021) Tool texturing for micro-turning applications - an approach using mechanical micro indentation. Mater Manuf Process 36(1):84-93

22. Dandekar CR, Shin YC (2009) Multi-step 3-D finite element modeling of subsurface damage in machining particulate reinforced metal matrix composites. Compos - A: Appl Sci Manuf 40(8):1231-1239

23. Tang DW, Zhang WM, Zhao RL, Lv XJ (2017) Machining of $\mathrm{SiCp} / \mathrm{Al}$ composites: effect of tool corner radius on residual stresses, cutting force and temperature. Adv Mat Res 1142:265-270

Publisher's Note Springer Nature remains neutral with regard to jurisdictional claims in published maps and institutional affiliations. 